\title{
Speech production assessment of mouth breathing children with hypertrophy of palatines and/or pharyngeal tonsils
}

\author{
Tamara Borox ${ }^{(1)}$ \\ Ana Paula Dassie Leite ${ }^{(1)}$ \\ Maria Fernanda Bagarollo(2) \\ Bruno Leonardo Freire de Alencar ${ }^{(3)}$ \\ Gilsane Raquel Czlusniak ${ }^{(1)}$
}

(1) Universidade Estadual do Centro-Oeste UNICENTRO Irati, Paraná, Brasil.

(2) Universidade Estadual de Campinas UNICAMP, Campinas, São Paulo, Brasil.

(3) Faculdade Evangélica do Paraná - FEPAR, Instituto de Pesquisas Médicas - IPEM e Hospital Universitário Evangélico de Curitiba - HUEC, Curitiba, Paraná, Brasil.

Conflict of interests: Nonexistent

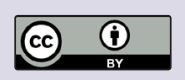

Received on: March 2, 2018

Approved on: July 17, 2018

Corresponding author:

Tamara Borox

Rua João Candido Ferreira, 1038 -

Rio Bonito

CEP: 84500-000 - Irati, Paraná, Brasil

E-mail: tamara.borox95@gmail.com

\section{ABSTRACT}

Objective: to evaluate the speech sound production of children diagnosed with a palatine mouth breathing and / or hypertrophic pharyngeal tonsil and compare it to that of a group of children that do not show any respiratory alterations, besides associating with age and sex.

Methods: a quantitative, cross-sectional, analytical and observational research. Children from five to twelve years old have took part of the study, 50 of them diagnosed as mouth breathers (research group - RG) and 50 with no respiratory alteration (control group - CG). Anamnesis and evaluation based on MBGR protocol was performed, focusing on the speech, supported by figures and with samples of automatic and spontaneous speech.

Results: there were no differences between the groups, taking into account the parents' complaint. Speech alterations, such as phonetic deflection, lingual interposition and distortions, and occlusion alterations were more frequent in RG. Speech alterations prevailed for males in $83 \%$ and the average age related to speech did not show any significance.

Conclusion: mouth breathing children present more alterations of speech sounds than those presented with no respiratory alteration, regardless of the age group, being more common in male children.

Keywords: Articulation Disorders; Mouth Breathing; Palatine Tonsil; Pharyngeal tonsil 


\section{INTRODUCTION}

Proper breathing is established by nasal airways up to the lungs, providing individuals with upper airways protection for their craniofacial growth and development, in addition to the maintenance of the normal performance of their stomatognathic functions ${ }^{1}$. Respiratory mode can be identified as nasal, with the prevalent use of the nasal cavities; oral breathing, by means of the prevalent oral cavity use, due to any nasal obstructions or habit; or mixed/oronasal breathing, when individuals use both breathing ways ${ }^{2}$ longer than six months ${ }^{3}$.

The exchange of nasal respiratory mode for oral one is quite common in the first years of life due to interfering factors ${ }^{4}$, such as organic changes: obstruction of the upper airways (rinitis ${ }^{5}$, hypertrophic palatine and/ or pharyngeal tonsils, deviation of septum, among others), or even non-organic changes, due to deleterious habits ${ }^{2,6}$.

The aforementioned disorders may have straight correlation with phonoaudiological changes. Specifically, in the orofacial motricity ${ }^{7}$, the degree of impairment is related to the time length and chronicity of the respiratory alteration ${ }^{8}$, causing several changes in individuals' lives, such as craniofacial modifications, sleep disorders, functional changes in the stomatognathic system and in the phono-articulatory organs ${ }^{9}$.

When mouth breathing is organic-related, surgical procedures are often advised by otorhinolaryngological specialists. Adenotonsillectomy, in order to remove hypertrophic palatine and pharyngeal tonsils, is the most performed surgical procedure in the world, and the commonest otorhinolaryngological surgery ${ }^{10}$. Tonsils evidence progressive growth during childhood, coming to a halt around seven years old. Surgery is recommended in case of chronic inflammation of those structures ${ }^{11}$.

Utterance is one of the stomatognathic functions and it is straight correlated to breathing. Therefore, speech is impaired due to improper breathing mode. Stomatognathic system must be anatomically and functionally stable for correct utterance, thus phonoarticulatory organs will be capable of performing their proper articulations ${ }^{12}$.

Motor activity for speech production entails all neuromuscular system, that is, it is submitted to the neurological system, and all of its related speechproduction structures must be completely functional and in perfect synchrony so that damages to intelligibility do not occur ${ }^{13,14}$.
Speech changes in mouth breathers may evolve from alterations in orofacial praxes, in addition to muscle tone mobility and posture of the orofacial structures, such as tongue, lips, cheeks, teeth and jaw ${ }^{15}$. In mouth breathers, the tongue is positioned in the inferior part of the oral cavity, which may provoke changes in muscles responsible for the utterance ${ }^{1}$. Oral respiratory mode is pointed as one of the causes for the development of malocclusion as a consequence of structural and bone changes, in such a way that both may bring about speech changes as the speech lisp ${ }^{16}$. Therefore, detailed speech assessment entails thorough evaluation of the stomatognathic system, once it greatly interferes in utterance production ${ }^{17}$. Moreover, the speech therapist needs to understand all interfering variables in the proper speech production, such as socioeconomic and environmental interventions ${ }^{18}$.

The study is justified for trying and minimizing the effects of probable mouth breathing-related alterations, which may persist even after surgical procedures, and will demand rehabilitative speech therapeutic treatment in order to re-establish nasal respiratory mode, requiring structural and functional adaptations.

From the exposed above, the research study objectified to analyze the association between mouth breathing and variables, such as complaint and (or) delay in the speech acquisition and alterations in utterance (distortions, omissions, substitutions and tongue interposition) in children diagnosed with hypertrophic palatine and/or pharyngeal tonsils, correlating them to the characteristics of dental occlusion and lingual frenulum. Moreover, it aimed to compare such results to the ones obtained by children without any alterations in the respiratory mode. As a complementary objective, it aimed to correlate plausible alterations to individuals' gender and age.

\section{METHODS}

The current research consists of an observational, analytical, cross-sectional, quantitative study. The research complied with the regulations of Resolution 466/2012 from the National Health Council on ethical conduct in human beings' research studies, and it was approved by the Ethics Board of the Universidade Estadual do Centro Oeste - UNICENTRO, opinion number 1.332.668.

The research was held with minors whose parents or legal guardians signed the Free Informed Consent Form. The participants also signed the Agreement 
Form, showing their approval to participate in the research.

Inclusion criteria for the research group were children between five and 12 years old, which considered that age group around 5 years old as the end of the complete phonological acquisition of the Brazilian Portuguese language ${ }^{19}$, as well as this timespan until incomplete 12 years old, once literature considers it the end of childhood ${ }^{20}$, to show the diagnosis for change in the respiratory mode, assessed by an otorhinolaryngological specialist, to be referred to adenoidectomy/ tonsillectomy, reporting complaint for over a year.

The assessed children were in a waiting list for the surgical procedure of removing the hypertrophic tonsils and/or adenoids, being referred to that waiting list after otorhinolaryngological assessment, clinical exam, mouth testing to screen the degree of palatine tonsils hyperplasia, also evaluating recurrent tonsillitis, acute tonsillitis, tonsil stone, cavum radiograph, and assessment by using flexible nasal fibro-endoscope $(3 \mathrm{~mm})$ for rhinopharyngeal screening, and oropharyngeal screening for upper pole hyperplasia of the palatine tonsils.

After clinical evaluation and imaging exams for surgical referral, patients underwent laboratory tests and ECG.

As for the participants' inclusion criteria in the control group, it was defined the same age group as for the research group; the individuals should not have been diagnosed with palatine and/or pharyngeal tonsil hypertrophy, no respiratory conditions (children and legal guardians' self-report), in addition, assessment of the respiratory mode was carried out by means of usual lip position during the evaluation, Glatzel mirror and mouth fluid retention. In case of any observed breathing impairments, the child was excluded from the research.

As exclusion criteria for both groups, diagnosis and/or self-reported neurological, hearing, syndromic, psychiatric, metabolic, endocrinological disorders, craniofacial malformations, language development delay, previous head and neck surgeries, and previous speech therapeutic treatment.

The sample comprised 100 participants, both genders, between five and 12 years old. The children were divided in in two groups, as follows: 50 children in the Research Group (RG) without any diagnosis of oral breathing and/or any complaints regarding respiratory disorders (self-reported by parents and child). Data collection was held with participants and legal guardians' agreement, being children from the Research Group (RG) assessed on the day of their medical appointment before surgery, and the children from the Control Group (CG) were assessed at the Speech-Language Teaching Clinic of the institution, and they belonged to the contact network of the researchers (family members, friends, acquaintances, etc.).

Regarding gender distribution, $62 \%$ of the children in the Research Group were male, and 38\% were female. In the Control Group (CG), they accounted for $50 \%$ for both genders. By comparing the groups, gender variable did not evidence statistically significant diversity $(p=0.227)$. Similarly, there was no disparity between the groups regarding age, that is, mean value was seven to nine years in the Research Group (RG), and eight to three years $(p=0.308)$ in the Control Group (CG).

Interfering variables in the current research were as follows: presence of non-nutritive suction, altered lingual frenulum, self-report of hearing complaints and occlusal disorders. It was opted for not omitting hearing complaints and occlusal disorders, as they are mouth breathing-related, and common among children from the Research Group (RG). Regarding non-nutritive suction and altered lingual frenulum, also observed in the greatest part of children from the same age group, such information was not omitted. However, as for the results, statistical analyses related to the interfering variables were held, comparing the Control Group (CG) and the Research Group (RG).

Evaluations were based on the anamnesis with parents and/or legal guardians of the participant minors in order to search for their history and disorders, such as: speech acquisition delay and speech disorders, as well as clinical assessment founded in the MBGR protocol ${ }^{21}$, which analyzes orofacial structures and functions of the stomatognathic system. The obtained data were stored in a data file.

Evaluations were carried out in the SpeechLanguage Teaching Clinic of the Institution, followed by a team from an extension project, monitored by a specialized teacher with a Doctoral Degree in the Area of Orofacial Motricity.

Regarding the evaluation of speech sound production, the following tests were performed: to name 35 phonetically selected figures entailing all the phonemes in the Brazilian Portuguese language in their diversified productions, utterance encompassing days of the week intermingled with numbers, and 
spontaneous conversations among the participants, with varied excerpts of conversations carried on during the sessions. Disregarding MBGR' distinctive tests for speech evaluation, it was chosen to gather data related to omission, substitution, distortion (lateral lisp and distortion of phoneme $/ r /$ ) and lingual interposition $(/ \mathrm{t} /, / \mathrm{d} /, / \mathrm{n} /, / \mathrm{l} /, / \mathrm{s} /, / \mathrm{z} /)$ whenever visual observation was possible. As all participants got the same results on all tests, presence of disorders was considered when occurrence was equal to $25 \%$ or over from the sample total in the assessed sound production. Samples were video recorded and submitted to further analysis by the research team, along with $\mathrm{PhD}$ supervisor in the area of Orofacial Motricity.

The collected data were statistically analyzed, validating the significance level of $5 \%(p<0.05)$. The tests used were: Test for Equality of Proportions Between Two Samples, Variance Analysis (ANOVA), and Pearson's Chi-Square Test.

\section{RESULTS}

As for the anamnesis data, it can be observed that most legal guardians from both groups do not report any current difficulties and/or delay in speech acquisition on the part of the children (CG $=14 \%$; $R G=$ $18 \% ; p=0.585$ ).

Table 1 shows the comparison between the groups to evaluate speech sound production, which points out higher number of alterations in the Research Group (GP
- 32\%), compared to the Control Group (CG - 14\%), a difference of $p=0.032$ between the groups.

As for the variance type analyzed in the speech sound production, isolated phonetic disorders prevailed in the Research Group (RG) (16\%) compared to the Control Group (CG) (2\%), evidencing the difference between them, $(p=0.014)$. Isolated phonetic, phonological alterations were similar between the groups, as visualized in Table 1.

The processes observed in the speech assessment were omission, substitution, distortion and tongue interposition. There was a difference between the groups for the distortion and tongue interposition variables, the higher number of alterations occurring in the Research Group. In the Research Group (RG), 12 children featured speech distortion, unlike the Control Group $(C G)$, with only three $(p=0.012)$. Similarly, tongue interposition during speech occurred in ten children from the Research Group (RG), and in three children from the Control Group (CG) (0.037). As for the substitution variable, $p$ value does not show any distinctions between the groups $(p=0.084)$.

Regarding the types of altered phonemes, considering the total number of participating children, it could be observed the prevalence of: /d/ $12 \%, / r / 11 \%, / \mathrm{J} / 9 \%$, /3/ $9 \%, / z / 8 \%$, /t/ $8 \%$.

As for the data on dental occlusion, it was possible to evidence a distinction between the groups, with $64 \%$ of the children from the Research Group (RG) featuring change, unlike $32 \%$ of the children from the Control Group (CG) $(p=0.001)$ - (Table 1). 
Table 1. Comparison between the research group and the control group in the speech assessment

\begin{tabular}{|c|c|c|c|c|c|c|}
\hline & & \multicolumn{2}{|c|}{ Control Group } & \multicolumn{2}{|c|}{ Research Group } & \multirow{2}{*}{ p-value } \\
\hline & & (n) & $(\%)$ & (n) & $(\%)$ & \\
\hline \multirow[t]{2}{*}{ Speech } & Altered & 7 & $14 \%$ & 16 & $32 \%$ & 0.032 \\
\hline & Normal & 43 & $86 \%$ & 34 & $68 \%$ & \\
\hline \multirow[t]{3}{*}{ Type of alteration } & phonetic & 1 & $2 \%$ & 8 & $16 \%$ & 0.014 \\
\hline & $\begin{array}{l}\text { phonetic and } \\
\text { phonological }\end{array}$ & 1 & $2 \%$ & 2 & $4 \%$ & 0.558 \\
\hline & phonological & 3 & $6 \%$ & 7 & $14 \%$ & 0.182 \\
\hline \multirow[t]{12}{*}{ Processes } & omission & & & & & \\
\hline & No & 45 & $90 \%$ & 39 & $78 \%$ & 0.102 \\
\hline & Yes & 5 & $10 \%$ & 11 & $22 \%$ & \\
\hline & substitution & & & & & \\
\hline & No & 46 & $92 \%$ & 40 & $80 \%$ & 0.084 \\
\hline & Yes & 4 & $8 \%$ & 10 & $20 \%$ & \\
\hline & distortion & & & & & \\
\hline & No & 47 & $94 \%$ & 38 & $76 \%$ & 0.012 \\
\hline & Yes & 3 & $6 \%$ & 12 & $24 \%$ & \\
\hline & $\begin{array}{l}\text { Lingual interposition } \\
(/ \mathrm{t} /, / \mathrm{d} / /, / \mathrm{n} /, / \mathrm{I} / / \mathrm{s} /, / \mathrm{z} /)\end{array}$ & & & & & \\
\hline & No & 40 & $80 \%$ & 47 & $94 \%$ & 0.037 \\
\hline & Yes & 10 & $20 \%$ & 3 & $6 \%$ & \\
\hline
\end{tabular}

Test for equality of proportions between two samples $(p<0.05)$.

In Tables 2 and 3 , the results of the additional analysis are shown, where speech data were associated with age and gender variables concomitantly. For the mentioned analysis, the total number of children was considered, disregarding the group they belonged to. Mean age of children with normal speech ( 7.43 years) and altered speech (8.31 years) were similar $(p=0.101)$ - (Table 2). About the correlation between speech alterations and gender variance, the results evidenced statistical difference $(p=0.003)$, prevalence of disorders in males $(83 \%)$, and normality in females $(52 \%)$, as shown in Table 3.

Table 2. Association between the presence or not of speech alteration and the age variable

\begin{tabular}{ccc}
\hline \multirow{2}{*}{ Age } & & Speech \\
\cline { 2 - 3 } & Altered & Normal \\
\hline Mean & 7.43 & 8.31 \\
Median & 7 & 8 \\
Standard Deviation & 1.97 & 2.30 \\
Min & 5 & 5 \\
Max & 12 & 12 \\
$\mathrm{~N}$ & 23 & 77 \\
$\mathrm{Cl}$ & 0.81 & 0.51 \\
\hline P-value & & \\
\hline
\end{tabular}

ANOVA Test $(p<0.05)$

Legend: $\mathrm{N}=$ Sample Number; $\mathrm{Cl}=$ Confidence Interval; Min = minimum value;

Max $=$ maximum value 
Table 3. Association between the presence or not of speech alteration and gender variable

\begin{tabular}{|c|c|c|c|c|c|c|}
\hline \multirow{3}{*}{ Gender } & \multicolumn{6}{|c|}{ Speech } \\
\hline & \multicolumn{2}{|c|}{ Altered } & \multicolumn{2}{|c|}{ Normal } & \multicolumn{2}{|c|}{ Total } \\
\hline & (N) & (\%) & (N) & (\%) & (N) & (\%) \\
\hline Female & 4 & $17 \%$ & 40 & $52 \%$ & 44 & $44 \%$ \\
\hline Male & 19 & $83 \%$ & 37 & $48 \%$ & 56 & $56 \%$ \\
\hline Total & 23 & $23 \%$ & 77 & $77 \%$ & 100 & $100 \%$ \\
\hline
\end{tabular}

P-value $=0.003$

Chi-square Test $(p<0.05)$.

In Table 4, the results of the interfering variables, adopted in this study, are shown. No statistical differences were verified between the Research Group (RG) and the Control Group (CG) on hearing complaint, lingual frenulum and non-nutritive suction $(p>0.05$ for all analyses). Difference was evidenced for the occlusion variable, where children from the Research Group (RG) showed greater occurrence of alterations than the Control Group (CG) $(p=0.001)$.

Table 4. Comparison between the groups, regarding the interfering variables for occlusion, hearing complaint, lingual frenulum and non-nutritive suction

\begin{tabular}{|c|c|c|c|c|c|c|}
\hline & \multicolumn{2}{|c|}{ Control Group } & \multicolumn{2}{|c|}{ Research Group } & \multirow{2}{*}{ p-value } \\
\hline & & (n) & (\%) & (n) & $(\%)$ & \\
\hline \multirow{2}{*}{ Non-nutritive suction } & No & 23 & $46 \%$ & 27 & $54 \%$ & \multirow{2}{*}{0.424} \\
\hline & Yes & 27 & $54 \%$ & 23 & $46 \%$ & \\
\hline \multirow{2}{*}{ Lingual frenulum } & Altered & 2 & $4 \%$ & 0 & $0 \%$ & \multirow{2}{*}{0.153} \\
\hline & Normal & 48 & $96 \%$ & 50 & $100 \%$ & \\
\hline \multirow{2}{*}{ Hearing complaint } & No & 11 & $57.90 \%$ & 31 & $62 \%$ & \multirow{2}{*}{0.755} \\
\hline & Yes & 8 & $42.10 \%$ & 19 & $38 \%$ & \\
\hline \multirow{2}{*}{ Occlusion } & Normal & 34 & $68 \%$ & 18 & $36 \%$ & \multirow{2}{*}{0.001} \\
\hline & Altered & 16 & $32 \%$ & 32 & $64 \%$ & \\
\hline
\end{tabular}

Teste de Igualdade de Duas Proporções $(p<0,05)^{*}$

\section{DISCUSSION}

Mouth breathing leads to disorders in the phonoarticulatory organs and in functions of the stomatognathic system, among them, speech changes. Therefore, studies related to the mentioned theme are essential, keeping in mind that such alterations are significant for the child development. Disregarding the etiology of the oral breathing, genetic factors and time length of the nasal obstruction may bring about several damages to child life ${ }^{22}$.

Speech acquisition and development are important processes in child life, and parents have an ultimate role in this period. Thus, it is essential that parents perceive their children's speech, as they spend longer time with them and may follow up the process, with early detection of probable alterations earlier. Parents are usually intuitive on any abnormalities and conclude that correct utterance must happen until 4 years old ${ }^{23}$. In the current study, it was verified that the most parents from the Research Group (RG), as well as from the Control Group (CG) did not report any delay or complaints in relation to their children's speech when questioned about it. These data may be justifiable once many phonetic alterations, such as lingual interposition, one of the most observed in this study, are imperceptible to lay people, unlike phonological disorders, which hinder speech intelligibility more frequently.

It was possible to observe, from the collected data, that children in the Research Group (RG) evidenced greater changes in the speech sound production than 
the Control Group (CG). The existing data corroborated the results of a prior study ${ }^{22}$, which showed that $31.2 \%$ of the children older than 5 years of age featured speech disorders related to oral breathing. However, such conclusions do not have thorough agreement, as reported by another research study, which did not evidence greater occurrence of speech alterations in children with mouth breathing when compared to children from the control group ${ }^{24}$.

Among the speech alterations, there are phonetic and phonological disorders. Phonetic disorders feature articulatory difficulties, ultimately caused by structural alterations, bone as well as muscle-related, thus bringing about dysfunctions in the phono-articulatory organs, impairing the speech sound production, and the anterior lisp is an example. Therefore, phonological disorders are characterized by the incorrect use of the speech segments, by analyzing other speakers in the linguistic community, unrelated to organic disorders ${ }^{25}$, causing difficulties in the perception, production or organization of the phonological system rules, generating speech sound substitutions or omissions after a certain age $^{26}$. Phonetic disorders were evidenced among the participants of the Research Group (RG) by comparing them to the Control Group (CG). The exposed data corroborate the results of certain studies, which claim that phonetic disorders can be originated from alterations in the stomatognathic system, quite common in cases of oral breathing ${ }^{25}$. Therefore, literature points out that such changes can be solved if the stomatognathic system is worked on, which is possible for the Research Group (RG) after undergoing adenotonsillectomy ${ }^{25}$.

Mouth breathers keep their lips parted longer, tongue on the floor of the mouth, causing hypofunction of the orofacial muscles ${ }^{2,27}$, thus impacting negatively in utterance. Following such a structural alteration, there may be impairment in the production of phonemes which demand certain articulatory points, such as phonemes $/ \mathrm{t} /, / \mathrm{d} /, / \mathrm{s} /, / \mathrm{z} /, / \mathrm{r} /, / / /^{28}$.

By analyzing the phonemes produced during speech, it was possible to visualize prevailed alterations in the following phonemes: /d/, /r/, /J/, /3/, /t/, /z/. Such alterations can be related to tone dysfunctions in the phono-articulatory organs, usually present in mouth breathers, despite the study did not focus on that kind of assessment².

According to the processes occurring during speech production, it was possible to observe more distortions and lingual interpositions in the Research
Group (RG). The obtained results corroborate data from other studies ${ }^{6,24}$, which identified the prevalence of the same processes claimed by the authors for impairing the stomatognathic system. According to the literature, hypertrophic palatine tonsils occupy the greatest part of the posterior portion in the oral cavity, thus influencing in the cases of lingual interposition/frontal lisp ${ }^{22}$.

The processes of omission and substitution did not evidence any differences between the researched groups. It should be pointed out that the mentioned processes occur during the normal phonological acquisition, but those strategies are kept in child speech due to the difficulty of dealing with the segment complexity ${ }^{25}$.

It is worth analyzing that the full acquisition of Brazilian Portuguese language occurs around five years of age ${ }^{19}$. The current study assessed children between five and 12 years of age, and did not evidence any statistical differences by relating mean age to speech production, similar to what is found in literature $^{6}$. Regarding the association between alterations in speech sound production and gender, the study verified male prevalence. Such data corroborate studies in the literature, in which boys evidence more speech delay and disorders than girls ${ }^{28}$. However, another study ${ }^{29}$ reported no gender difference regarding speech acquisition and disorders among Brazilian children. Thus, further research studies concerning that variable are suggested, distinguishing phonetic disorders from phonological disorders so that the subject is elucidated.

As previously mentioned in the methods and results, some variables were assumed as interfering variables in the present study, justifying that they are quite common in mouth breathing children referred to adenotonsillectomy. Speech can be impaired by several factors, such as oral breathing and its etiology, food processes, occlusion, frequency and timespan of deleterious oral habits, hearing, stimulation ${ }^{22}$, and personality, as shyness during the assessment ${ }^{6}$.

In this study, there was no difference between the groups for the variable non-nutritive suction, which minimizes a remote hypothesis that disorders in the speech sound production could be caused by deleterious habits, not oral breathing.

Chronic mouth breathing impairs craniofacial development, hindering jaw and teeth growth ${ }^{30}$. When comparing the groups regarding dental occlusion, statistical difference with greater occurrence of alterations verified in the Research Group (RG). That result evidences that more common occlusion disorders are observed in mouth breathing children, and may 
influence in the result of speech alteration in that group, as shown by the results in the current research. Malocclusion is considered one of the features of oral breathers, and may cause difficulties in phonetic/articulatory production ${ }^{30}$, as such disorders may stem from muscular and/or skeletal dysfunctions, such as bone alterations, face shaping, dental absence, bite changes, which may hinder the correct articulation point of the phonemes, thus resulting in lateral, anterior lisp and other phonemic distortions ${ }^{31}$. A study, which aimed to analyze the correlation between respiratory mode, occlusion and speech, observed the relation between occlusion alteration and the presence of speech articulation disorder variables ${ }^{32}$.

Mouth breathing due to hypertrophic palatine and pharyngeal tonsils cause alterations, in varied degrees and impacts, on lip, mouth tone and posture, and in the mobility of the soft palate, impairing swallowing, speech and phonatory functions. After adenoidectomy and/or tonsillectomy, spontaneous improvement in certain aspects occurs, however, in many cases, it is necessary to undergo speech therapy in order to rehabilitate impaired organs and functions, in addition to a multidisciplinary intervention ${ }^{22,30}$.

Preventive treatments and health promotion should be carried out in order to minimize the resulting effects from an incorrect respiratory pattern. Multidisciplinary intervention is essential, as that alteration demands other professionals, apart from the speech therapist, aiming at promoting proper quality of life for those children.

It can be pointed out as the study limitations: the impossibility to correlate assessment data of speech sound production to more detailed otorhinolaryngological characteristics concerning the clinical assessment; the impossibility to obtain more objective assessment parameters for speech production.

Further studies are suggested to correlate speech disorders to probable dysfunctions in the stomatognathic and neurovegetative systems. It is also possible to increase the number of research participants and expand the age range to be studied, in addition to children's follow-up after they have undergone adenotonsillectomy and speech therapy.

\section{CONCLUSION}

Mouth breathing children feature more alterations in speech sound production than those who do not present changes in the respiratory mode, mainly regarding phonetic aspects and lingual interposition.
Such disorders occur disregarding the age range and are more common in male children.

\section{REFERENCES}

1. Silva LK, Brasolotto AG, Félix GB. Breathing function in subjects with Dentofacial deformities. Rev. CEFAC. 2015;17(3):854-63.

2. Andrada e Silva MA, Marchesan IQ, Ferreira LP, Schmidt R, Ramires RR. Posture, lips and tongue tone and mobility of mouth breathing children. Rev. CEFAC. 2012;14(5):853-60.

3. Costa Junior C, Sabino HAC, Miura CS, Azevedo $\mathrm{CB}$, Menezes UP, Valera FCP et al. Atopy and adenotonsillar hypertrophy in mouth breathers from a reference center. Braz. j. otorhinolaryngol. 2013;79(6):663-7.

4. Machado PG, Mezzomo CL, Badaró AFV. A postura corporal e as funções estomatognática em crianças respiradoras orais: um revisão de literatura. Rev. CEFAC. 2012;14(3):553-65.

5. Cunha RA, Cunha DA, Bezerra LÂ, Melo ACC, Peixoto DM, Tashiro $T$ et al. Nasal aeration and respiratory muscle strength in mouth breathers' children. Rev. CEFAC. 2015;17(5):1432-40.

6. Campanha SMA, Fontes MJF, Santos JLF. Dispnéia em indivíduos com asma, rinite alérgica e respiração oral. Rev. CEFAC. 2012;14(2):268-73.

7. Angst OVM, Liberalesso KP, Wiethan FM, Mota $\mathrm{HB}$. Prevalence of speech-language disorders in kindergarten children of public schools and the social indicators. Rev. CEFAC. 2015;17(3):727-33.

8. Baldrighi SEZM, César CPHAR, Brito AF, Ferreira GG, Rodrigues MRC, Nascimento LT et al. Orofacial myofunctional profile of children seen in the pediatric dental clinic of the University Hospital of Aracaju/SE. Distúrb. Comun. 2015;27(1):85-96.

9. Lemos CM, Wilhelmsen MSW, Mion OG, Mello Junior JF. Alterações funcionais do sistema estomatognático em pacientes com rinite alérgica: estudo caso-controle. Rev. Bras. Otorrinolaringol. 2009;75(2):268-74.

10. Rebechi G, Pontes TE, Braga EL, Matos WM, Rebechi F, Matsuyama C. Estudos histopatológicos de cirurgias de adenotonsilectomias são realmente necessários? Int. Arch. Otorhinolaryngol. 2013;17(4):387-9.

11. Alvo VA, Sauvalle CM, Sedano MC, Gianini VR. Amigdalectomía y adenoidectomía: conceptos, técnicas y recomendaciones. Rev. Otorrinolaringol. Cir. Cabeza Cuello. 2016;76(1):99-110. 
12. Martinelli RLC, FornGlaro ÉF, Oliveira CJM, Ferreira LMDB, Rehder MIBC. Correlações entre alterações de fala, respiração oral, dentição e oclusão. Rev. CEFAC. 2011;13(1):17-26.

13. Marchesan IQ, Martinelli RLC. Terapia das alterações da fala no respirador oral. In: Félix BG, Tessitore A, Amaral AKFJ, Alves GAS, Silva HJ, Marchesan IQ et al. (orgs). A fala nos diversos contextos da motricidade orofacial. São José dos Campos, SP: Pulso Editorial, 2015. p. 144.

14. Barberena LS, Portalete CR, Simoni SN, Prates ACM, Keske-Soares M, Mancopes R. Electropalatography and its correlation to tongue movement ultrasonography in speech analysis. CoDAS. 2017;29(2):e20160106.

15. Gubiani MB, Keske-Soares M. Phonological evolution of children with speech disorders submitted to different therapeutic approaches. Rev. CEFAC. 2014;16(2):663-71.

16. Pérez GAS, López RMB, López LVR. Prevalencia de hábito de respiración oral como factor etiológico de maloclusión en escolares del Centro, Tabasco. Revista ADM. 2014;71(6):285-9.

17. Gubiani MB, Carli CM, Keske-Soares M. Phonological disorder and alterations of orofacial praxis and the stomatognathic system. Rev. CEFAC. 2015;17(1):134-42.

18. Piva F, Moraes JK, Vieira VR, Silva AER, Hendges RM, Sari GT. Evaluation of the association between indicators of oral health and sociodemographic variables in children with orofacial clinical signs of chronic mouth breathing. Audiol. Commun. Res. 2014;19(3):236-42.

19. Mezzomo CL, Luiz SW. Interference of the linguistic variant in the repair strategies used during the phonological acquisition process. J. Soc. Bras. Fonoaudiol. 2012;24(3):239-47.

20. Brasil. Ministério da Saúde. Estatuto da Criança e do Adolescente / Ministério da Saúde. - 3. ed. Brasília: Editora do Ministério da Saúde, 2008. 96 p. 85-334-1058-1.

21. Genaro KF, Berretin-Felix, Rehder MIBC, Marchesan IQ. Avaliação miofuncional orofacial Protocolo MBGR. Rev. CEFAC. 2009;11(2):237-55.

22. Hitos SF, Arakaki R, Solé D, Weckx LL. Oral breathing and speech disorders in children. J. Pediatr. 2013;89(4):361-5.

23. Wolff GS, Goulart BNG. Percepção dos pais sobre os distúrbios fonoaudiológicos na infância. J. Hum. Growth Dev. 2013;23(2):177-83.
24. Costa M, Valentim AF, Becker HMG, Motta AR. Findings of multiprofessional evaluation of mouth breathing children. Rev. CEFAC. 2015;17(3):864-78.

25. Ceron MI, Gubiani MB, Oliveira CR, Gubiani MB, Keske-Soares M. Prevalence of phonological disorders and phonological processes in typical and atypical phonological development. CoDAS. 2017;29(3):e20150306.

26. Monteiro VR, Brescovici SM, Delgado SE. A ocorrência de ceceio em crianças de oito a 11 anos em escolas municipais. Rev Soc Bras Fonoaudiol. 2009;14(2):212-8.

27. Indrusiak CS, Rockenbach SP. Prevalência de desvio fonológico em crianças de 4 a 6 anos de escolas municipais de educação infantil de canoas RS. Rev. CEFAC. 2012;14(5):943-51.

28. Silva MK, Ferrante C, Van Borsel J, Pereira MMB. Phonological acquisition of brazilian portuguese in children from Rio de Janeiro. J. Soc. Bras. Fonoaudiol. 2012;24(3):248-54.

29. Silva LK, Brasolotto AG, Berretin-Felix G. Breathing function in subjects with dentofacial deformities. Rev. CEFAC. 2015;17(3):854-63.

30. Balieiro FBA, Azevedo R, Chiari BM. Aspects of stomatognathic system before and after adenotonsillectomy. CoDAS. 2013;25(3):229-35.

31. Marchesan IQ. Alterações de fala de origem musculoesquelética. In: Ferreira LP, Befi-Lopes DM, Limongi SCO (orgs). Tratado de Fonoaudiologia. São Paulo: Roca, 2004. p. 292-303.

32. Berwig LC, Silva AMT, Busanello AR, Almeida FL, Bolzan GP, Hennig TR et al. Alterações no modo respiratório, na oclusão e na fala em escolares: ocorrências e relações. Rev. CEFAC. 2010;12(5):795-802. 